\title{
Differential involvement of hippocampal calcineurin during learning and reversal learning in a Y-maze task
}

\author{
Robbert Havekes, ${ }^{1}$ Ingrid M. Nijholt, Paul G.M. Luiten, and Eddy A. Van der Zee \\ Department of Molecular Neurobiology, University of Groningen, Haren 9750 AA, The Netherlands
}

\begin{abstract}
The regulation and function of the calcium-dependent phosphatase calcineurin ( $\mathrm{CaN}$, protein phosphatase 2B) in learning and memory remain unclear, although recent work indicates that $\mathrm{CaN}$ may play a differential role in training and reversal training. To gain more insight into the involvement of $\mathrm{CaN}$ in these two types of learning, hippocampal CaN activity, protein levels, and expression patterns were studied in mice subjected to a reference memory version of the Y-maze task. We show that (1) training but not habituation induces a decrease in cytosolic $\mathrm{CaN}$ activity, (2) the recovery of cytosolic CaN activity is reversal training specific and does not reflect normal restoration of basal levels unrelated to subsequent learning, (3) cytosolic protein levels for the catalytic subunit of $\mathrm{CaN}$ (CaNA) are decreased at the early phase of training, but not at the early phase of reversal training, (4) CaNA immunoreactivity in the dorsal hippocampus is enhanced in the CAl and CA3 area (but not in the dentate gyrus [DG] or subiculum [SUB]) only during reversal training. These findings indicate that memory formation is accompanied by reduced CaN activity, whereas adapting to changes in a familiar environment is accompanied by restored $\mathrm{CaN}$ activity. Moreover, reversal training selectively affects hippocampal CA3 and CA1 regions, suggesting a specific function of these hippocampal subregions in reversal learning.
\end{abstract}

It is widely accepted that the hippocampus is a structure that is essential for encoding both spatial and nonspatial information (Morris et al. 1982; Moyer Jr. et al. 1990; Bunsey and Eichenbaum 1996). This includes not only the formation of trial specific, short-term memory also known as "working memory," but also incremental learning (a process occurring over multiple trials leading to the formation of long-lasting reference memory of information constant over trials).

Reversal learning can be used to induce a shift in behavioral response patterns (Deacon et al. 2002; Reisel et al. 2002; Palencia and Ragozzino 2004) and is a well-suited task to investigate which processes are involved in adapting to changes in a familiar environment. Bannerman et al. (2003), for instance, showed that mice lacking the Glur1 subunit of the glutamatergic AMPA receptor were unimpaired during acquisition of a reward-based spatial discrimination task and thus were capable to form a hippocampus-dependent reference memory. However, these mutants showed a deficit during reversal training in which mice had to learn that the reward was relocated to the previously unbaited arm of the maze and had to shift their response pattern.

A central issue, not only in the formation of memory but also in adapting to changes in a familiar environment, is the identification of both positive and negative regulators controlling synaptic plasticity (Abel et al. 1998). One of the mechanisms controlling synaptic plasticity is the balance between phosphorylation and dephosphorylation of specific substrates by respectively protein kinases and protein phosphatases (Soderling and Derkach 2000).

Protein phosphatases serve as negative regulators counteracting the actions of protein kinases by the induction and maintenance of long-term depression (LTD), down-regulation of synaptic strength, and spine shrinkage (Mulkey et al. 1993, 1994; Zhou et al. 2004). However, the function of synaptic weakening

'Corresponding author.

E-mail r.havekes@rug.nl; fax +31503632331.

Article published online before print. Article and publication date are at http:// www.learnmem.org/cgi/doi/10.1101/lm.323606. (e.g., LTD) in memory storage is still not clear. One hypothesis proposed by Malleret et al. (2001) is that synaptic weakening has a negative effect on memory storage. A second view is that both increase and decrease of synaptic strength are a prerequisite for optimal memory storage (Migaud et al. 1998). Furthermore, it has been postulated that phosphatases have an equally dynamic and critical function similar to kinases in the activity-dependent alteration of synaptic transmission and that phosphatases have an important role in neuronal functioning (Winder and Sweatt 2001).

Especially in the case of adapting to changes in a familiar environment, protein phosphatases could be key players. Indications for this role of protein phosphatases came from several studies using either genetic or pharmacological approaches. These studies focused on calcineurin $(\mathrm{CaN})$, a multifunctional calcium-dependent phosphatase which is present at high levels in the hippocampus. CaN can directly dephosphorylate several target proteins (Mansuy 2003) and modulates a large variety of proteins indirectly, functioning as an antagonist of cAMPdependent protein kinase (PKA) (Mulkey et al. 1994). Zeng et al. (2001) showed that forebrain specific CaN knock-out mice were specifically impaired in learning a changed platform location in a Morris water maze (MWM). In line with the hypothesis that $\mathrm{CaN}$ is needed to adapt to changes in a familiar environment, Runyan et al. (2005) showed that pharmacological inhibition of $\mathrm{CaN}$ activity in the prefrontal cortex inhibited rats from learning new platform positions in the MWM during consecutive days. Finally, Lin et al. (2003a) revealed that blocking CaN activity in the basolateral amygdala during extinction training in a fear conditioning paradigm inhibited the extinction of previously formed fear memory.

To gain more insight into the involvement of $\mathrm{CaN}$ during various phases of training and reversal training, hippocampal CaN activity, protein levels, and expression patterns were studied in mice subjected to a reference memory version of the Y-maze task. Our findings show that learning and reversal learning are processes with differential involvement of CaN. 


\section{Results}

\section{Behavioral performance in the Y-maze during training and reversal training}

Mice were assigned to one of the following groups: N: naive, home cage controls $(n=16)$; T3: training three sessions $(n=18)$; T7: training seven sessions $(n=19)$; RT3: training seven sessions, reversal training three sessions $(n=15)$; RT6: training six sessions, reversal training six sessions $(n=17)$.

At the beginning of training (Session 1), all groups performed at chance level with group averages ranging from $51.04 \pm 7.83 \%$ to $58.33 \% \pm 6.36$ percentage correct trials, indicating that there was no preference for either of the two arms. Performance improved with ongoing training $\left(F_{6,288}=25.368\right.$, $P<0.001)$, resulting in a score ranging from $84.21 \%( \pm 3.93 \%)$ to $86.46 \%( \pm 4.62 \%)$ at the end of training (Session 7$)$. No differences between the experimental groups were found (ANOVA $F<1$; Fig. 1).

After training, the RT3 and RT6 group received a reversal training, with the reward located in the previously unbaited arm. The percentage of correct trials in these groups dropped to respectively $18.75 \%( \pm 7.59 \%)$ and $24.51 \%( \pm 5.91 \%)$ during the first reversal training, demonstrating that mice still had a preference for the formerly rewarded arm. Gradually, mice shifted their preference to the newly rewarded arm, and after six sessions the same level of performance was reached as was found during the initial training (RT6 group, $81.25 \% \pm 7.99 ; F_{5,80}=27.934$, $P<0.001$; Fig. 1).

\section{Hippocampal cytosolic CaN activity is decreased during training but restored during reversal training}

In Experiment 1, hippocampal CaN activity in the cytosol and pellet fraction was assayed by measuring organic Pi release from a phosphopeptide substrate at different time points immediately after the last training or reversal training (Fig. 2). At the early phase of training, hippocampal cytosolic CaN activity decreased from $2.6 \pm 0.1 \mathrm{nmol} \mathrm{Pi} / \mathrm{min} / \mathrm{mg}$ in the $\mathrm{N}$ group $(n=8)$ to $1.7 \pm 0.2 \mathrm{nmol} \mathrm{Pi} / \mathrm{min} / \mathrm{mg}$ in the T3 group $(n=8, P<0.01)$. At the end of training, cytosolic $\mathrm{CaN}$ activity remained decreased in the T7 group to $1.4 \pm 0.3 \mathrm{nmol} \mathrm{Pi} / \mathrm{min} / \mathrm{mg}(n=9, P<0.01)$. There was no correlation between behavioral performance and

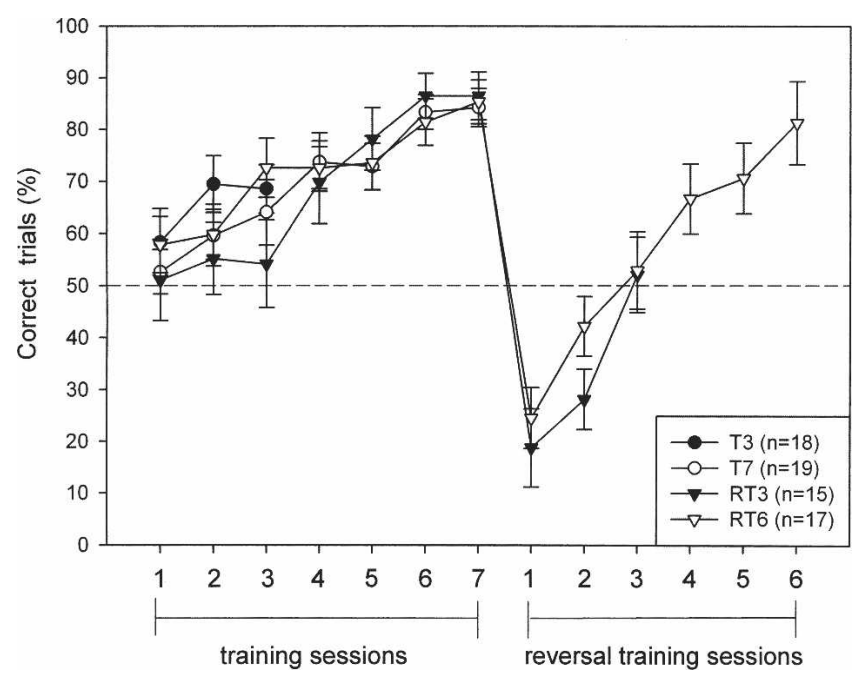

Figure 1. Performance in the $\mathrm{Y}$-maze during training and reversal training. The percentage of correct trials per session is shown for the T3 $(n=18), \mathrm{T} 7(n=19), \mathrm{RT} 3(n=15)$, and RT6 $(n=17)$ groups.
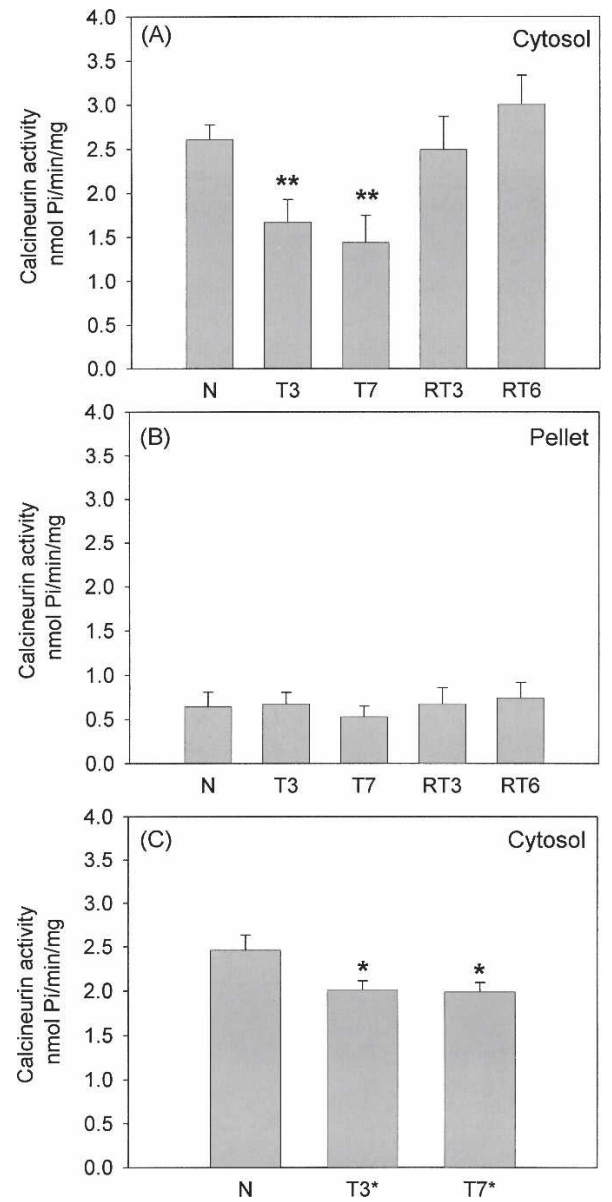

Figure 2. Hippocampal cytosolic CaN activity is decreased during training but not during reversal training in the $\mathrm{Y}$-maze. Mice were assigned to the following groups: Experiment 1: $\mathrm{N}(n=8)$ naive; $\mathrm{T} 3(n=8)$; T7 $(n=9) ; \mathrm{RT} 3(n=8)$; and RT6 $(n=8)$. Experiment 2: $\mathrm{N}(n=8)$ naive; $\mathrm{H}$ $(n=8) ; \mathrm{T}^{*}(n=8) ; \mathrm{T}^{*}(n=7) . \mathrm{H}, \mathrm{T} 3$, and T3* groups received three sessions of training while the T7, T7*, RT3, and RT6 received seven sessions of training (in the case of the $\mathrm{H}$ group, the maze was unbaited). Thereafter, the RT3 and RT6 group received respectively three and six sessions of reversal training. Immediately after the last training trial, hippocampal $\mathrm{CaN}$ activity was measured in all groups except for the $\mathrm{T} 3^{*}$ group and $\mathrm{T}^{*}$ group which were left in their home cage for respectively 4 and $3 \mathrm{~d}$. (A) Experiment 1: CaN activity in the cytosol fraction. (B) Experiment 1: CaN activity in the pellet fraction. (C) Experiment 2: CaN activity in the cytosol fraction. ${ }^{*} P<0.05,{ }^{* *} P<0.01$.

reduction in calcineurin activity in the T3 group (data not shown).

However, after three and six sessions of reversal training, cytosolic CaN activity was back to baseline level of naive mice (RT3 $n=8: 2.5 \pm 0.4 \mathrm{nmol} \mathrm{Pi} / \mathrm{min} / \mathrm{mg}, \mathrm{RT} 6: n=8: 3.0 \pm 0.3$ $\mathrm{nmol} \mathrm{Pi} / \mathrm{min} / \mathrm{mg}, P>0.2$ in both cases) (Fig. $2 \mathrm{~A}$ ).

In the pellet fraction, $\mathrm{CaN}$ activity in the $\mathrm{N}$ group was, on average, five times lower than was found in the cytosol fraction (Fig. 2B). No changes in CaN activity were detected in this fraction during either training or reversal training (ANOVA $F<1$ ).

In Experiment 2, we tested whether only habituation to the Y-maze also decreased cytosolic CaN activity. Mice ( $\mathrm{H}$ group, $n=8$ ) were allowed to enter the maze during three sessions (similar to the T3 group), however no food rewards were placed in either of the two goal arms. After three sessions, the mice did not show a preference for either of the two arms (data not shown). There was an indication for a decrease in this habituation group

\section{Learning \& Memory}

www.learnmem.org 
compared with the control group, although it was not significant (ANOVA $F<1$; Fig. 2C).

We also examined if the restoration of cytosolic CaN activity to baseline levels during reversal training was reversal trainingspecific. Two additional groups of mice received three and seven sessions of training (T3*: $n=8$ and $\mathrm{T}^{*}: n=7$, respectively). Learning curves were comparable to those from the T3 and T7 groups (data not shown); after training, mice of both groups were left in their home cage for respectively five and three days (matching the total number of training days of the RT6 group). In both the $\mathrm{T}^{*}$ and $\mathrm{T}^{*}$ groups, cytosolic CaN activity levels remained decreased in the $\mathrm{T}^{*}(2.0 \pm 0.1 \mathrm{nmol} \mathrm{Pi} / \mathrm{min} / \mathrm{mg}$, $P<0.05)$ and $\mathrm{T}^{*}(2.0 \pm 0.1 \mathrm{nmol} \mathrm{Pi} / \mathrm{min} / \mathrm{mg}, P<0.05)$ compared to the control group ( $n=8: 2.46 \pm 0.2 \mathrm{nmol} \mathrm{Pi} / \mathrm{min} / \mathrm{mg})$, showing that reversal training specifically restores calcineurin acitivity (Fig. 2C).

\section{Hippocampal protein levels for the CaN catalytic subunit (CaNA) are decreased at the early phase of training but not at the early phase \\ of reversal training}

Hippocampal protein levels for CaNA were determined in the cytosol and pellet fraction using Western blotting. Figure 3A shows representative immunoreactive bands for cytosolic CaNA. Actin was used to control protein loading. CaNA levels were decreased in the T3 group $(n=11, P<0.005)$, but returned to baseline level in the T7 group $(n=10, P=0.1)$ compared with levels found in the naive mice ( $n=8$; Fig. 3B). During reversal training, CaNA protein levels were not decreased in the cytosol fraction and were comparable with that of the naive mice (RT3, $n=7$; RT6, $n=9, P>0.5$ in both cases). In the pellet fraction, CaNA protein levels were not affected by training or reversal training $(F<1$; Fig. 3C). No differences were found in total protein levels of CaNA (ANOVA $F<1$; Fig. 3D). Furthermore, comparison of CaNA protein levels in the cytosol and pellet fraction of the $\mathrm{N}$ group also revealed no differences (ANOVA $F<1$, data not shown).

\section{Differential CaNA expression within the dorsal hippocampus during training and reversal training} To assess whether training and/or reversal training induced alterations in immunogenicity of CaNA within the hippocampus, CaNA immunoreactivity (CaNA-ir) of naive mice was compared with that of the T7 and RT6 group. A representative photomicrograph of CaNA-ir in the dorsal hippocampus of a control animal is shown in Figure 4A. CaNA-ir was most abundant in the principal cell bodies with the different areas ranked as follows: subiculum (SUB) $>$ CA1 > CA3 > dentate gyrus (DG). The dendrites of the pyramidal cells in the SUB and CA1 area were intensely stained, while moderate labeling was found in the dendrites in the CA3 area. Weak CaNA-ir labeling was found in the granular cell bodies and their dendrites. The relative optical densities (ODs) of CaNA-ir for the N, T7, and RT6 groups are shown in Figure 5. Post hoc comparisons revealed that CaNA-ir was increased in the RT6 group as compared with the naive group. This was found in both cell bodies and dendrites of the CA1 and CA3 area (for CA1 and CA3 cell bodies and CA1 dendrites: $P<0.01$; CA3 dendrites: $P<0.005)$. In contrast to the CA1 and CA3 pyramidal cell layers, no differences were found in the granular cell bodies and dendrites or in the cell bodies and dendrites of the SUB. In summary, these data show that changes in CaNA-ir due to reversal training are specifically located in the CA1 and CA3 area.
(A)
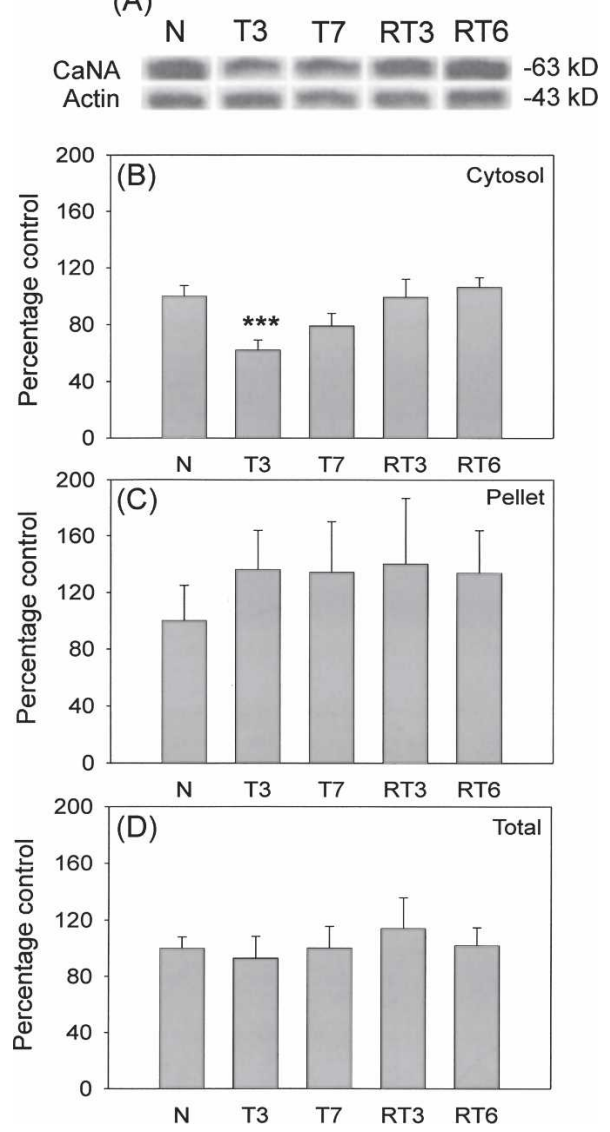

Figure 3. Hippocampal CaNA protein level is decreased at the early stage of training, but not at the early stage of reversal training in the Y-maze. $(A)$ Representative immunoreactive bands for CaNA and actin. (B) Cytosolic CaNA protein levels, relative to actin levels during the course of training and reversal training. At the early stage of training, cytosolic CaNA levels were decreased (T3 $n=10, P<0.005)$. Cytosolic CaNA levels were comparable with levels of the control group at the end of training and during reversal training (T7 $n=10$; RT3 $n=7$; RT6 $n=9, P>0.05$ in all cases). (C,D) No differences were found in the protein levels of CaNA in the pellet or in the total fraction (ANOVA $F<1$ ). ${ }^{* * *} P<0.005$.

\section{Discussion}

Studies using genetic approaches revealed that increasing CaN activity inhibited the formation of a behavioral response pattern (Mansuy et al. 1998a), while a reduction of CaN activity enhanced the formation of a response pattern (Malleret et al. 2001). Furthermore, complete abolishment of forebrain CaN activity disrupted specifically the shifting of response patterns (Zeng et al. 2001). However, so far it has not been investigated in detail to what extent hippocampal cytosolic and/or membrane bound CaN activity, protein levels, and expression patterns are altered during training and reversal training in mice not genetically modified. In the present study we show for the first time that (1) cytosolic hippocampal CaN activity is reduced during training and restored to baseline levels during reversal training, (2) cytosolic CaNA protein levels were reduced at the early phase of training, but not at the early phase of reversal training. CaNA protein levels in the pellet fraction were not affected, and (3) CaNA-ir was enhanced specifically in the CA1 and CA3 area only during reversal training. These results show that $\mathrm{CaN}$ is differentially involved in memory formation and adaptation to changes in a familiar environment in a Y-maze and indicate a specific function of the hippocampal CA1 and CA3 regions in reversal learning. 
(A)

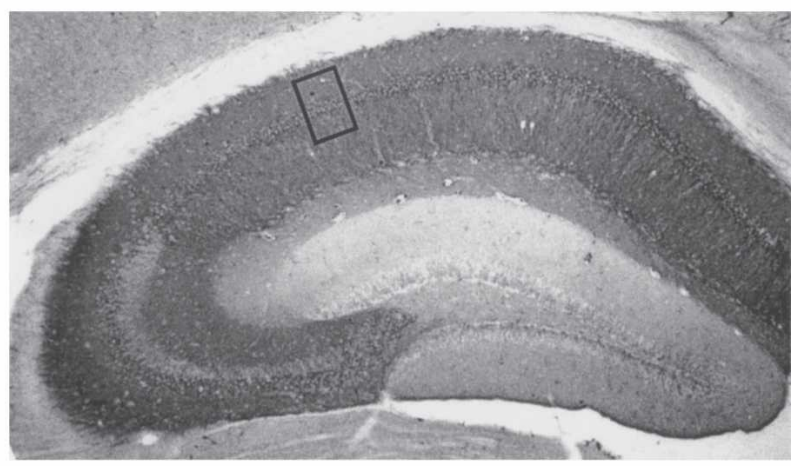

(B)
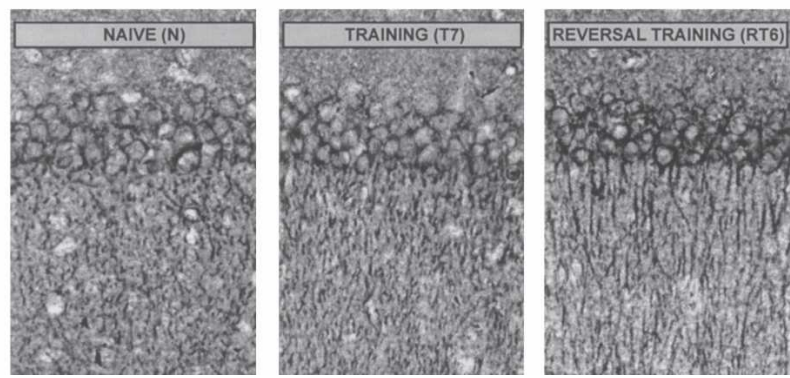

Figure 4. Representative immunoreactive labeling for CaNA-ir in the dorsal hippocampus. (A) Depicted from a control animal. (B) Enlargements of the CA1 region (see insert in $A$ for location) are taken from a representative control $(\mathrm{N})$, trained (T7), and reversal trained (RT6) animals.

We observed a decrease in hippocampal CaN activity in the cytosol fraction during training. In addition, we found a slight decrease in CaN activity due to habituation in an unbaited Ymaze, although it was not statistically significant. Together these data suggest that the decrease in cytosolic CaN activity is training specific and only to a small degree related to exposure to a novel context. Decreasing hippocampal CaN activity could alter the balance of kinase/phosphatase activity toward phosphorylation of protein substrates responsible for synaptic transmission, especially in the case of PKA-dependent processes (Mansuy et al. 1998a,b; Winder et al. 1998). The decreased CaN activity could result in reduced dephosphorylation and diminished internalization of AMPA receptors (Lee et al. 2003) and decreased NMDA receptor desensitization (Lieberman and Mody 1994; Tong et al. 1995; Shi et al. 2000). It could also have various downstream effects, such as the dephosphorylation of the transcription factor CREB, by a reduction in protein phosphatase 1 activity (PP1) through the dephosphorylation of PP1 inhibitors (Halpain et al. 1990; Mulkey et al. 1994; Bito et al. 1996). Altogether, decreasing CaN activity could lead to enhancement of memory formation.

In contrast to training, cytosolic CaN activity levels were not decreased during reversal training but were restored to baseline levels, although the learning curve shows that animals do form a reference memory for the new location of the food reward. These findings suggest that restoration of $\mathrm{CaN}$ was essential to adapt to changes in a familiar environment. The function of this restored cytosolic CaN activity during reversal training remains to be determined. Several studies revealed that novel information (in contrast with previously acquired information) generates a second independent memory trace whilst the original trace remains intact (Bouton and Nelson 1994; Berman and Dudai 2001). It could very well be that CaN plays a role in this second memory trace (which encodes the novel location of the food reward).
Alternatively the restored cytosolic $\mathrm{CaN}$ activity could also play a role in the weakening of the original trace through a negative feedback loop which down-regulates kinase activity and weakens the original memory trace as has been shown for the extinction of fear memory (Lin et al. 2003a,b)

Interestingly, CaN activity was changed specifically in the cytosol fraction, but not in the pellet fraction. This finding suggests a specific involvement of cytosolic $\mathrm{CaN}$ in learning and reversal learning-evoked synaptic plasticity, which may be surprising considering that a large fraction of calcineurin is found attached to targeting proteins at the membrane and known to be tightly regulated and implicated in synaptic plasticity. However, several studies showed specific changes in CaN activity in the cytosol fraction, suggesting that cytosolic CaN can play an important role in regulating synaptic plasticity. Foster et al. (2001) showed that cytosolic CaN activity was enhanced with ageing and accompanied by a reduction in the phosphorylation state of CaN substrates like CREB as well as reduced behavioral performance. In addition, a more recent paper by Yang et al. (2005) showed that enhancing cytosolic calcineurin activity in the mouse visual cortex blocks the shift in ocular dominance normally induced by monocular deprivation. They also showed that this impairment could be rescued by restoring normal cytosolic calcineurin activity. Together with our own findings, these results suggest that cytosolic CaN activity can play a pivotal role in synaptic plasticity and memory formation.

CaN activity in the control group was substantially lower in the pellet fraction as compared with the cytosol fraction, while no differences were found in CaNA protein levels of both fractions. Low $\mathrm{CaN}$ activity in the pellet fraction could be due to the inhibition of its activity by binding to anchoring proteins like AKAP79/150, which can translocate toward substrates at the post-synaptic densities and is known to reduce the activity of CaN (Dell'Acqua et al. 2002).

CaNA protein levels were decreased only at the early phase of training, but not at the beginning of the reversal training. The decrease was not accompanied by an increase in the pellet fraction, indicating that training and reversal training do not change total CaN protein levels. At the end of training, cytosolic protein levels were restored, while cytosolic CaN activity remained decreased. These findings indicate that $\mathrm{CaN}$ is regulated through multiple mechanisms, resulting in nonparallel effects on activity and protein levels during training in the Y-maze. It suggests that the protein levels of calcineurin are increased, but that the newly produced calcineurin is not activated (or is inhibited from being active) and thus does not affect calcineurin activity levels. CaN activity can be inhibited through several mechanisms like binding to anchoring proteins as mentioned above, but also through a decrease in $\mathrm{Ca}^{2+}$ (Klee et al. 1998), or by a reduction in calmodulin levels, for instance due to trapping by activated calcium-calmodulin-dependent kinase II (Hubbard and Klee 1989; Hashimoto et al. 1990; Meyer et al. 1992). It remains to be determined which of these mechanisms down-regulates cytosolic CaN activity during the formation of memory in the Y-maze test.

Besides the differences in CaN activity during training and reversal training, we showed that CaNA-ir is enhanced during reversal training, specifically in the CA1 and CA3 area of the hippocampus. This increase in immunoreactivity is possibly due to conformational changes resulting in an increased access of the antibody to the epitope, and hence does not reflect an increase in total protein levels (a finding previously shown to be the case for other systems; Van der Zee et al. 1997). This putative conformational change of CaNA is specifically induced by reversal training and CaNA activity returning to baseline levels, since the decrease in CaN activity during training was not accompanied by any change in CaNA-ir or any change in CaNA protein levels.

\section{Learning \& Memory \\ www.learnmem.org}




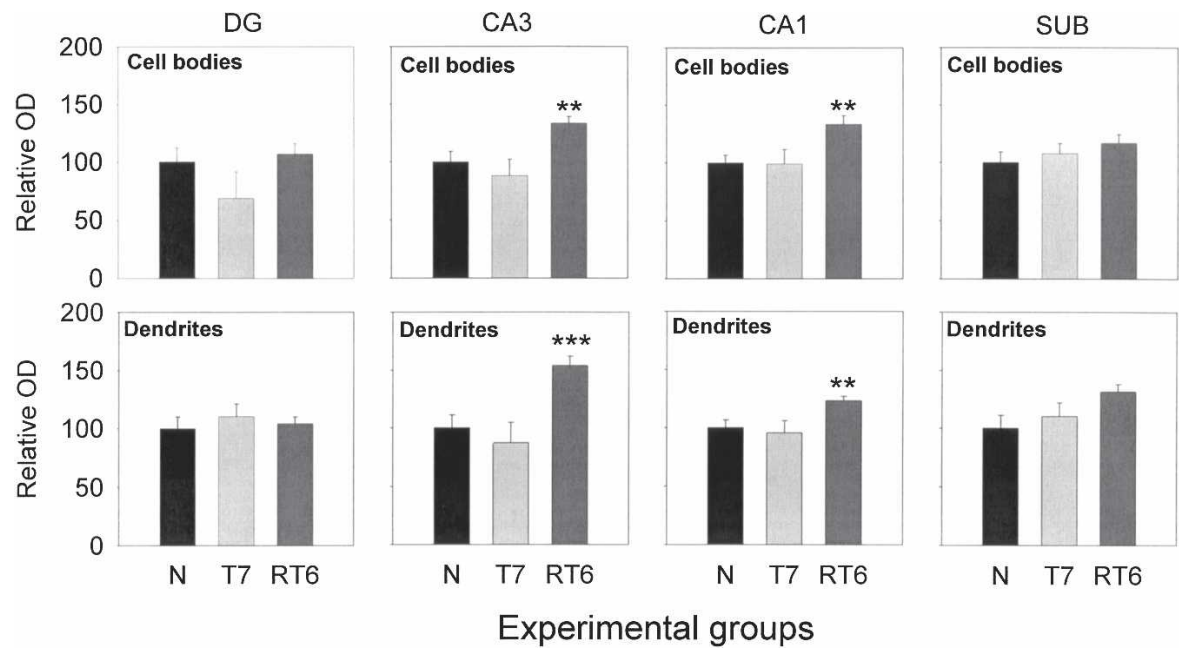

Figure 5. Reversal training enhances CaNA-ir in the CA1 and CA3 areas of the reversal trained group. CaNA-ir was measured in the following areas of the dorsal hippocampus: DG, CA3, CA1, and SUB. Compared with the control group, CaNA-ir was specifically increased in the RT6 group in the pyramidal cell bodies and dendrites of the CA1 and CA3 areas but not in the DG and SUB. No increases were found in the T7 group. ${ }^{* *} P<0.01,{ }^{* *} P<0.005$.

It is widely accepted that the hippocampus is a key structure in memory storage and recall; however, increasing evidence suggests that the hippocampus is also involved in novelty detection, by comparing previously formed information with novel information (Lisman and Otmakhova 2001). In the case of the Y-maze task, the comparison should be made between the originally learned location of the food reward (during training) and the novel location of the food reward (during reversal training). The comparison of expectations based on previous experience (arising from the CA3 area) and novel information arising from the entorhinal cortex is suggested to take place in the CA1 area (Lisman and Otmakhova 2001). CaNA-ir was specifically increased in the CA3 and CA1 areas during reversal training, suggesting that CaN could be important to overcome the mismatch between previously stored information and the novel information and could thus be necessary for the shift in behavioral response pattern. CaN may dephosphorylate specific substrates, locally inducing LTD and thereby weakening specific CA3-CA1 and CA1entorhinal cortex connections, resulting in weakening or suppression of the original memory trace.

Taken together, our data show that $\mathrm{CaN}$ is involved in the formation of hippocampus-dependent memory and adapting to changes in a familiar environment and suggest that CaN plays a differential role in these processes. Memory formation is accompanied by reduced CaN activity, whereas the adaptation to changes in a familiar environment is accompanied by restored CaN activity. Restored CaN activity may predominantly take place in the CA1 and CA3 areas, linked to specific memory functions of these hippocampal subregions.

\section{Materials and Methods}

\section{Animals and housing conditions}

A total of 116 male C57BL/6J mice (Harlan, Horst, the Netherlands), 12-15 wk old, were individually housed in standard macrolon cages equipped with a removable slot which could be locked on to the Y-maze. Subjects were maintained on a 12-h light/12-h dark cycle (lights on at 7:30 a.m.) with food (hopefarm standard rodent pellets) and water ad libitum. A layer of sawdust served as bedding. Subjects were food-deprived to a maximum of $90 \%$ of their individual body weight calculated under ad libitum feeding conditions, starting four days before the start of the exfrom the end of the arms to prevent visual inspection for food presence from a distance. The experimental room was decorated with visual cues, which served as distal spatial cues.

\section{Habituation procedure}

During the first day, subjects of the experimental groups were placed in the center of the Y-maze and allowed to explore the maze for 4 min (first habituation). During the second habituation trial on the same day, the home cage was locked on to the start arm of the Y-maze. Mice were given the opportunity to freely enter the maze without handling. Starting from the home cage, subjects could explore one of the two arms (the other arm was closed). The open arm was baited with small crumbs of food $(0.05-0.1 \mathrm{~g})$ placed at the end of the arm. When the reward was consumed and the mouse retreated to the home cage, the home cage was disconnected from the Y-maze. The third habituation trial was similar to the second habituation trial, but now the previously blocked arm was accessible, and the previously accessible arm was blocked. The second and third habituation trials were given to inhibit the development of a preference for either of the two arms forming the Y of the maze.

\section{Test procedure}

After habituation, training sessions consisting of six trials each were given. During the entire training, either the right or left arm was baited. When a subject visited one of the two accessible arms, the non-visited arm was closed. After the subject retreated to the home cage, the start arm connected to the home cage was subsequently blocked so that the subject could not re-enter the maze. After cleaning all arms with a dampened paper towel, and rebaiting one of the two arms, the subject was again allowed to explore either the right or left arm. A visit to the baited arm was recorded as a correct trial. The T3 and T3* groups received three sessions divided over two days, while the T7, T7*, RT3, and RT6 groups received seven sessions of training, divided over four days. The $\mathrm{H}$ group also received three sessions of pseudotraining; both goal arms of the maze were unbaited. Immediately after training, the RT3 and RT6 groups received respectively three and six additional sessions divided over two and three days but now with the food reward located in the previously unrewarded arm (reversal training). The total numbers of testing days for the different groups are as follows: H, T3, T3*: 2 d; T7 and T7*: 4 d; RT3: 6 d; RT6: 7 d.

Immediately after the last session, animals of the H, T3, T7, 
RT3, RT6 groups were deeply anesthetized with a mixture of $\mathrm{CO}_{2}$ and $\mathrm{O}_{2}$ followed by a quick dissection of the brain. Animals of the $\mathrm{T}^{*}$ and $\mathrm{T}^{*}$ groups served as control groups for the RT7 group, and were left in their cages respectively 4 and $3 \mathrm{~d}$ after the training to match for the total number of training days of the RT7 group. After 4 and $3 \mathrm{~d}$ the brains of the $\mathrm{T}^{*}$ and $\mathrm{T}^{*}$ groups were collected. Right and left hemispheres were separated and the hippocampal tissue was either processed for CaN activity analysis, Western blot analysis, or immunocytochemistry. CaN activity measurements were performed in two separate sets both including a control group: Experiment 1: N, T3, T7, RT3, and RT7; Experiment 2: N, H, T3*, and T7*.

\section{CaN activity assay}

Hippocampi (weighing $\sim 0.017-0.020 \mathrm{~g}$ ) were homogenized in ice-cold lysis buffer $(50 \mathrm{mM}$ Tris- $\mathrm{HCl} \mathrm{pH} 7.5,50 \mathrm{mM} \mathrm{NaCl}, 10$ mM EGTA, 5 mM EDTA, 1 mM PMSF, $20 \mu \mathrm{g} / \mathrm{mL}$ leupeptin, and $4 \mathrm{\mu g} / \mathrm{mL}$ aprotinin), using a pellet pestle (Sigma-Aldrich). After centrifugation $\left(100,000 \mathrm{~g}, 60 \mathrm{~min} 5^{\circ} \mathrm{C}\right)$, pellet fractions were resuspended in ice-cold lysis buffer. The protein concentrations were measured using the Bradford method (Bradford 1976). Afterward, samples were stored at $-80^{\circ} \mathrm{C}$.

Phosphatase assay was performed in triplet according to the protocol provided by the manufacturer of the CaN assay kit (Promega). After removal of endogenous phosphatases using desalting columns, hippocampal cytosol and pellet samples (respectively 5 and $10 \mu \mathrm{g}$ protein per sample) were added to the reaction buffer (50 mM imidazole pH 7.2, 0.2 mM EGTA, $10 \mathrm{mM} \mathrm{MgCl}_{2}$ $1 \mathrm{mM} \mathrm{NiCl}, 50 \mu \mathrm{g} / \mathrm{mL}$ calmodulin, $0.02 \%$-mercaptoethanol) and $\mathrm{CaN}$ substrate (sequence, $\mathrm{RRA}(\mathrm{pT}) \mathrm{VA}$ ). The reaction mixture was incubated at $30^{\circ} \mathrm{C}$ for $10 \mathrm{~min}$ followed by $20 \mathrm{~min}$ at room temperature. The reaction was terminated by the addition of 50 $\mu \mathrm{L}$ Molybdate Dye/Additive mixture. After $15 \mathrm{~min}$ at room temperature, optical densities of the samples were measured at 635 $\mathrm{nm}$ using a microplate reader (model 550, Biorad). The CaN activity was expressed in nanomoles of Pi released per minute per milligram of substrate. CaN activity for the cytosol and pellet fraction were assayed during separate sessions.

\section{Western blotting}

Hippocampi were quickly homogenized in ice-cold lysis buffer 18 $\mu \mathrm{L} / \mathrm{mg}$ tissue $(50 \mathrm{mM}$ Tris- $\mathrm{HCl} \mathrm{pH} 7.5,50 \mathrm{mM} \beta$-mercaptoethanol, $10 \mathrm{mM}$ EGTA, $5 \mathrm{mM}$ EDTA, $1 \mathrm{mM}$ PMSF, $10 \mathrm{mM}$ benzamidine). The resulting homogenates were centrifuged for $60 \mathrm{~min}$ at $100,000 \mathrm{~g} 5^{\circ} \mathrm{C}$. The supernatants were collected for use as cytosol fractions. Pellets were resuspended in lysis buffer $(20 \mu \mathrm{L} / \mathrm{mg}$ tissue) and the resulting suspensions were used as pellet fractions. The protein concentrations were measured using the Bradford method (Bradford 1976). Subsequently SDS sample buffer $(50 \%$ glycerin, $321.5 \mathrm{mM}$ Tris/HCl pH 6.8, 10\% SDS, 25\% $\beta$-mercaptoethanol, $0.1 \%$ bromphenol blue) was added, followed by 5 min heat denaturation at $95^{\circ} \mathrm{C}$. Afterward, samples were stored at $-80^{\circ} \mathrm{C}$.

Ten micrograms of protein were resolved in 10\% SDSpolyacrylamide gels, blotted electrophoretically to Immobilon-P transfer membrane (Millipore), and blocked overnight in blocking buffer $(0.1 \%$ Tween-20, $0.2 \%$ I-block, Tropix, in phosphate buffered saline [PBS, $\mathrm{pH} 7.4]$ ) at $5^{\circ} \mathrm{C}$. For the detection of the protein levels of CaN, membranes were incubated with antiCaNA (1:20,000, CaN $\alpha$-subunit, Sigma) and anti-actin (1:20,000, MP biomedicals) in buffer (containing $0.05 \%$ Tween-20, $0.1 \%$ I-block, Tropix, in PBS) for $2 \mathrm{~h}$. Membranes were rinsed with blocking buffer (twice) and incubated with secondary antibody $(1: 10,000$, goat-anti-mouse alkaline phosphatase, Tropix) in buffer (containing 0.05\% Tween-20, 0.1\% I-block, Tropix, in PBS) for $30 \mathrm{~min}$ at room temperature. Following rinsing with blocking buffer $(3 \times)$, membranes were rinsed in assay buffer $(0.1 \mathrm{M}$ diethanolamine, $1 \mathrm{mM} \mathrm{MgCl}_{2}, \mathrm{pH} 10.0$ ) for $2 \times 5 \mathrm{~min}$ at room temperature. For chemoluminescent labeling, membranes were incubated with Nitroblock II (1:40, Tropix) in assay buffer, rinsed with assay buffer (twice), and finally incubated with CDP star substrate $(1: 1,000$, Tropix) in assay buffer for $5 \mathrm{~min}$ at room tem- perature. CaN protein level for the cytosol and pellet fraction were blotted during separate sessions.

The immunoreactive bands were captured on autoradiography film (Kodak X scientific image film). Densitometric scans of the immunoreactive bands were digitized and quantified using a Quantimet 500 image analysis system (Leica). Totals were calculated by combining the quantified values for the cytosol and pellet fraction.

\section{Immunocytochemistry}

Brains were immersion-fixated in $2 \%$ paraformaldehyde at $4^{\circ} \mathrm{C}$. After $18 \mathrm{~h}$, brains were stored in PBS (pH 7.4) with $0.1 \%$ sodiumazide at $5^{\circ} \mathrm{C}$. Before sectioning on a cryostat the brains were cryoprotected in 30\% phosphate buffered sucrose for $36 \mathrm{~h}$ at room temperature. Coronal brain sections $(20 \mu \mathrm{m})$ were collected and stored in PBS with $0.1 \%$ sodium-azide. After rinsing in PBS $(3 \times)$ and incubation in $0.4 \% \mathrm{H}_{2} \mathrm{O}_{2}(30 \mathrm{~min})$ followed by rinsing in PBS $(3 \times)$, sections were preincubated in $5 \%$ horse serum (Jackson immuno research laboratories, West Grove, PA, USA) in PBS for $20 \mathrm{~min}$ at room temperature. After preincubation, sections were incubated in mouse monoclonal anti-calcineurin ( $\alpha$-subunit, 1:1,500; Sigma) in $1 \%$ horse serum and $0.1 \%$ azide in $\mathrm{PBS}$ at $37^{\circ} \mathrm{C}$ for $2 \mathrm{~h}$. Incubation was continued at $5^{\circ} \mathrm{C}$ for three days. Sections were then rinsed in PBS $(3 \times)$ and preincubated with 5\% normal goat serum (Jackson Immuno Research Laboratories) in PBS; sections were incubated overnight in biotinylated goat-anti-mouseIgG (1:500; Jackson Immuno Research Laboratories) at $5^{\circ} \mathrm{C}$. After rinsing with $\mathrm{PBS}(3 \times)$, sections were incubated with the avidinbiotin-horseradish peroxidase complex (1:500 ABC kit, Vector laboratories) for $2 \mathrm{~h}$ at room temperature. Finally, after washing in PBS for two days, sections were processed with diaminobenzidine $\left(0.02 \%\right.$ in PBS) with $100 \mu \mathrm{L} 0.1 \% \mathrm{H}_{2} \mathrm{O}_{2}$ as a reaction initiator. Processing was visually monitored and stopped by rinsing in PBS $(3 \times)$. Optical densities (OD) of CaN immunolabeling were measured in brain sections containing the dorsal hippocampus. The OD is expressed in arbitrary units corresponding to gray levels using a Quantimet 550 image analysis system (Leica). The value of background labeling was measured in the stratum moleculare (inner blade) of the DG together with the optical tract. The OD of the area of interest was related to the background value by the formula $\left[\left(\mathrm{OD}_{\text {area }}-\mathrm{OD}_{\text {background }}\right) / \mathrm{OD}_{\text {background }}\right]$, thus reducing the influence of the variability in background staining among sections.

\section{Statistical analysis}

Analysis of the behavioral data was performed using repeated measures analysis of variance (ANOVA). Statistical analysis of the ODs and integrated optical densities (IOD; surface $\times$ gray level) of respectively immunocytochemistry and Western blot data as well as the activity assay data was performed with one-way ANOVAs. When necessary, post hoc comparisons between control and experimental groups were made using independent samples $t$-test. During quantification steps for activity assay, Western blotting, and immunocytochemistry, the experimenter was blind to the group assignment of the individual animal. Values were expressed as mean \pm SEM. A $P<0.05$ was used as criterion for significance.

\section{Acknowledgments}

We thank Josée Plantinga for her assistance with the protein phosphatase assay. This work was supported by The Netherlands Organization for Scientific Research (NWO-Vernieuwingsimpuls E.A.V.d.Z, Grant 016.021.017).

\section{References}

Abel, T., Martin, K.C., Bartsch, D., and Kandel, E.R. 1998. Memory suppressor genes: Inhibitory constraints on the storage of long-term memory. Science 279: 338-341.

Bannerman, D.M., Deacon, R.M., Seeburg, P.H., and Rawlins, J.N. 2003. GluR-A-Deficient mice display normal acquisition of a hippocampus-dependent spatial reference memory task but are impaired during spatial reversal. Behav. Neurosci. 117: 866-870. 
Berman, D.E. and Dudai, Y. 2001. Memory extinction, learning anew, and learning the new: Dissociations in the molecular machinery of learning in cortex. Science 291: 2417-2419.

Bito, H., Deisseroth, K., and Tsien, R.W. 1996. CREB phosphorylation and dephosphorylation: $\mathrm{A} \mathrm{Ca}^{2+}$ - and stimulus duration-dependent switch for hippocampal gene expression. Cell 87: 1203-1214.

Bouton, M.E. and Nelson, J.B. 1994. Context-specificity of target versus feature inhibition in a feature-negative discrimination. J. Exp. Psychol. Anim. Behav. Process. 20: 51-65.

Bradford, M.M. 1976. A rapid and sensitive method for the quantitation of microgram quantities of protein utilizing the principle of protein-dye binding. Anal. Biochem. 72: 248-254.

Bunsey, M. and Eichenbaum, H. 1996. Conservation of hippocampal memory function in rats and humans. Nature 379: 255-257.

Deacon, R.M., Bannerman, D.M., Kirby, B.P., Croucher, A., and Rawlins, J.N. 2002. Effects of cytotoxic hippocampal lesions in mice on a cognitive test battery. Behav. Brain Res. 133: 57-68.

Dell'Acqua, M.L., Dodge, K.L., Tavalin, S.J., and Scott, J.D. 2002. Mapping the protein phosphatase-2B anchoring site on AKAP79. Binding and inhibition of phosphatase activity are mediated by residues 315-360. J. Biol. Chem. 277: 48796-48802.

Foster, T.C., Sharrow, K.M., Masse, J.R., Norris, C.M., and Kumar, A. 2001. Calcineurin links $\mathrm{CA}^{2+}$ dysregulation with brain aging. J. Neurosci. 21: 4066-4073.

Halpain, S., Girault, J.A., and Greengard, P. 1990. Activation of NMDA receptors induces dephosphorylation of DARPP-32 in rat striatal slices. Nature 343: 369-372.

Hashimoto, Y., Perrino, B.A., and Soderling, T.R. 1990. Identification of an autoinhibitory domain in calcineurin. J. Biol. Chem. 265: 1924-1927.

Hubbard, M.J. and Klee, C.B. 1989. Functional domain structure of calcineurin A: Mapping by limited proteolysis. Biochemistry 28: $1868-1874$.

Klee, C.B., Ren, H., and Wang, X. 1998. Regulation of the calmodulin-stimulated protein phosphatase, calcineurin. J. Biol. Chem. 273: 13367-13370.

Lee, H.K., Takamiya, K., Han, J.S., Man, H., Kim, C.H., Rumbaugh, G., Yu, S., Ding, L., He, C., Petralia, R.S., et al. 2003. Phosphorylation of the AMPA receptor GluR1 subunit is required for synaptic plasticity and retention of spatial memory. Cell 112: 631-643.

Lieberman, D.N. and Mody, I. 1994. Regulation of NMDA channel function by endogenous $\mathrm{Ca}^{2+}$-dependent phosphatase. Nature 369: 235-239.

Lin, C.H., Yeh, S.H., Leu, T.H., Chang, W.C., Wang, S.T., and Gean, P.W. 2003a. Identification of calcineurin as a key signal in the extinction of fear memory. J. Neurosci. 23: 1574-1579.

Lin, C.H., Yeh, S.H., Lu, H.Y., and Gean, P.W. 2003b. The similarities and diversities of signal pathways leading to consolidation of conditioning and consolidation of extinction of fear memory. $J$. Neurosci. 23: 8310-8317.

Lisman, J.E. and Otmakhova, N.A. 2001. Storage, recall, and novelty detection of sequences by the hippocampus: Elaborating on the SOCRATIC model to account for normal and aberrant effects of dopamine. Hippocampus 11: 551-568.

Malleret, G., Haditsch, U., Genoux, D., Jones, M.W., Bliss, T.V., Vanhoose, A.M., Weitlauf, C., Kandel, E.R., Winder, D.G., and Mansuy, I.M. 2001. Inducible and reversible enhancement of learning, memory, and long-term potentiation by genetic inhibition of calcineurin. Cell 104: 675-686.

Mansuy, I.M. 2003. Calcineurin in memory and bidirectional plasticity. Biochem. Biophys. Res. Commun. 311: 1195-1208.

Mansuy, I.M., Mayford, M., Jacob, B., Kandel, E.R., and Bach, M.E. 1998a. Restricted and regulated overexpression reveals calcineurin as a key component in the transition from short-term to long-term memory. Cell 92: 39-49.

Mansuy, I.M., Winder, D.G., Moallem, T.M., Osman, M., Mayford, M., Hawkins, R.D., and Kandel, E.R. 1998b. Inducible and reversible gene expression with the rtTA system for the study of memory. Neuron 21: 257-265.

Meyer, T., Hanson, P.I., Stryer, L., and Schulman, H. 1992. Calmodulin trapping by calcium-calmodulin-depdendent protein kinase. Science 256: $1199-1202$.

Migaud, M., Charlesworth, P., Dempster, M., Webster, L.C., Watabe, A.M., Makhinson, M., He, Y., Ramsay, M.F., Morris, R.G., Morrison, J.H., et al. 1998. Enhanced long-term potentiation and impaired learning in mice with mutant postsynaptic density-95 protein. Nature 396: 433-439.

Morris, R.G., Garrud, P., Rawlins, J.N., and O'Keefe, J. 1982. Place navigation impaired in rats with hippocampal lesions. Nature 297: 681-683.

Moyer Jr., J.R., Deyo, R.A., and Disterhoft, J.F. 1990. Hippocampectomy disrupts trace eye-blink conditioning in rabbits. Behav. Neurosci. 104: $243-252$.

Mulkey, R.M., Herron, C.E., and Malenka, R.C. 1993. An essential role for protein phosphatases in hippocampal long-term depression. Science 261: 1051-1055.

Mulkey, R.M., Endo, S., Shenolikar, S., and Malenka, R.C. 1994. Involvement of a calcineurin/inhibitor-1 phosphatase cascade in hippocampal long-term depression. Nature 369: 486-488.

Palencia, C.A. and Ragozzino, M.E. 2004. The influence of NMDA receptors in the dorsomedial striatum on response reversal learning. Neurobiol. Learn. Mem. 82: 81-89.

Reisel, D., Bannerman, D.M., Schmitt, W.B., Deacon, R.M., Flint, J., Borchardt, T., Seeburg, P.H., and Rawlins, J.N. 2002. Spatial memory dissociations in mice lacking GluR1. Nat. Neurosci. 5: 868-873.

Runyan, J.D., Moore, A.N., and Dash, P.K. 2005. A role for prefrontal calcium-sensitive protein phosphatase and kinase activities in working memory. Learn. Mem. 12: 103-110.

Shi, J., Townsend, M., and Constantine-Paton, M. 2000. Activity-dependent induction of tonic calcineurin activity mediates a rapid developmental downregulation of NMDA receptor currents. Neuron 28: 103-114.

Soderling, T.R. and Derkach, V.A. 2000. Postsynaptic protein phosphorylation and LTP. Trends Neurosci. 23: 75-80.

Tong, G., Shepherd, D., and Jahr, C.E. 1995. Synaptic desensitization of NMDA receptors by calcineurin. Science 267: 1510-1512.

Van der Zee, E.A., Kronforst-Collins, M.A., Maizels, E.T., Hunzicker-Dunn, M., and Disterhoft, J.F. 1997. Gamma Isoform-selective changes in PKC immunoreactivity after trace eyeblink conditioning in the rabbit hippocampus. Hippocampus 7: 271-285.

Winder, D.G. and Sweatt, J.D. 2001. Roles of serine/threonine phosphatases in hippocampal synaptic plasticity. Nat. Rev. Neurosci. 2: 461-474.

Winder, D.G., Mansuy, I.M., Osman, M., Moallem, T.M., and Kandel, E.R. 1998. Genetic and pharmacological evidence for a novel, intermediate phase of long-term potentiation suppressed by calcineurin. Cell 92: 25-37.

Yang, Y., Fischer, Q.S., Zhang, Y., Baumgärtel, K., Mansuy, I.M., and Daw, N.W. 2005. Reversible blockade of experience-dependent plasticity by calcineurin in mouse visual cortex. Nat. Neurosci. 8: 791-796.

Zeng, H., Chattarji, S., Barbarosie, M., Rondi-Reig, L., Philpot, B.D., Miyakawa, T., Bear, M.F., and Tonegawa, S. 2001. Forebrain-specific calcineurin knockout selectively impairs bidirectional synaptic plasticity and working/episodic-like memory. Cell 107: 617-629.

Zhou, Q., Homma, K.J., and Poo, M.M. 2004. Shrinkage of dendritic spines associated with long-term depression of hippocampal synapses. Neuron 44: 749-757.

Received May 17, 2006; accepted in revised form July 21, 2006. 


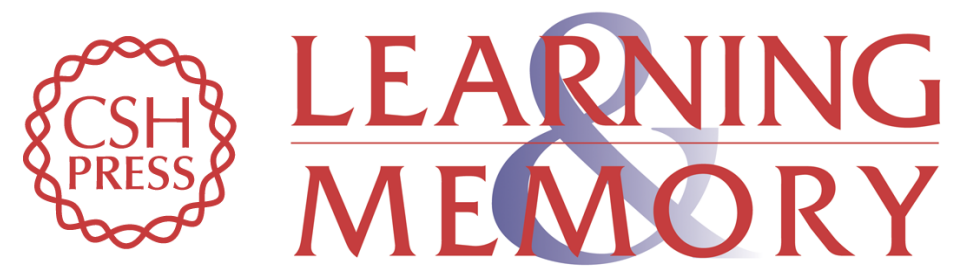

\section{Differential involvement of hippocampal calcineurin during learning and reversal learning in a Y-maze task}

Robbert Havekes, Ingrid M. Nijholt, Paul G.M. Luiten, et al.

Learn. Mem. 2006, 13: originally published online November 13, 2006

Access the most recent version at doi:10.1101/lm.323606

References

This article cites 41 articles, 12 of which can be accessed free at:

http://learnmem.cshlp.org/content/13/6/753.full.html\#ref-list-1

License

Email Alerting Service
Receive free email alerts when new articles cite this article - sign up in the box at the top right corner of the article or click here. 